\title{
Anti-Hyperlipidemic and Myocardial Enhancing Effects of Berberine in High Fat Diet/Streptozotocin- Induced Diabetic Rats; Possible Role of Adiponectin
}

\author{
Marwa M Abdel-Rahman ${ }^{1}$, Ayman M Mahmoud ${ }^{2 *}$, Nermin A Bastawy ${ }^{1}$ and Hassan M Eissa ${ }^{1}$ \\ ${ }^{1}$ Physiology Department, Faculty of Medicine, Cairo University, Egypt \\ ${ }^{2}$ Physiology Division, Zoology Department, Faculty of Science, Beni-Suef University, Egypt
}

Submission: December 06 2016; Published: January 24, 2017

*Corresponding author: Ayman M Mahmoud, Physiology Division, Zoology Department, Faculty of Science, Beni-Suef University, Egypt,

Tel: +201144168280; E-mail: ayman.mahmoud@science.bsu.edu.eg

Abstract

Aim: Berberine (BBR) is an isoquinoline alkaloid with promising anti-diabetic effect. The current study aimed to investigate the antihyperlipidemic and myocardial protective effect of BBR in high fat diet (HFD)/streptozotocin(STZ)-induced type 2 diabetic rats, highlighting the role of adiponectin.

Materials and Methods: Rats were fed a HFD for 4 weeks followed by a single intraperitoneal injection STZ (35mg/kg body weight). Diabetic rats were treated either with $50 \mathrm{mg} / \mathrm{kg}$ or $100 \mathrm{mg} / \mathrm{kg}$ BBR for 4 weeks.

Results: The present results showed a significant increase in fasting and post-prandial glucose levels with concomitant declined serum insulin and liver glycogen levels in diabetic rats. Serum levels of total cholesterol, triglycerides and free fatty acids (FFAs) showed a significant increase in the diabetic rats. Treatment with BBR significantly ameliorated serum glucose, insulin and lipids, and liver glycogen content. In addition, diabetic rats exhibited significantly increased serum AST, CK-MB and LDH, and cardiovascular risk indices, an effect that was markedly reversed following treatment with BBR. Oral supplementation of BBR significantly increased serum levels of adiponectin.

Conclusion: The ameliorative effect of BBR on carbohydrate and lipid variables in diabetes may be attributed to its insulin releasing capacity, lipid lowering effect, and increasing adiponectin levels.

Keywords: Berberine; Adiponectin; Free fatty acids; diabetes; High fat diet

\section{Introduction}

Type 2 diabetes mellitus (T2DM), the frequent form of diabetes, represents more than $90 \%$ of all diabetic patients [1]. Insulin resistance and impaired insulin secretion are two main characteristics of type 2 diabetes [2]. Insulin resistance in T2DM could be provoked by glucotoxicity, oxidative stress, lipotoxicity and inflammation [3]. Recently, the International Diabetes Federation (IDF) reported that the number of diabetic patients was 415 million in 2015 and is expected to rise to 642 million by 2040 [4]. If ineffectively controlled in diabetic patients, chronic hyperglycemia can cause serious complications in different organs [4]. Diet, exercise and several pharmacological agents are treatment approaches for type 2 DM. However, the use of currently used pharmacological agents is associated with adverse side effects such as weight gain, hypoglycemia and edema [5]. Therefore, search for effective alternatives with minimal or no side effects became a necessity.
Berberine (BBR), an isoquinoline alkaloid originally isolated from Coptischinensis (Huanglian), showed several pharmacological effects including, antioxidant, anti-inflammatory, anticancer, antimicrobial and hepato protective properties [6-10]. Reducing hyperglycemia was also among the beneficial effects of BBR $[11,12]$ however, the exact anti-diabetic mechanism is not completely understood. Insulin resistance and T2DM have been associated with dysfuncton in adipocytes [13]. Studies have demonstrated the role of adipose tissue in energy expenditure and insulin sensitivity [14] which is mediated through the secretion of diverse adipocytokines such as adiponectin $[13,15]$. Reduced adiponectin levels can provoke insulin resistance $[13,15]$. We hypothesized that the increase in circulating adiponectin levels may mediate, at least in part, BBR's anti-diabetic activity. Therefore, this study was undertaken to investigate the modulatory role of BBR on adiponectinand hyperlipidemia in high fat diet (HFD)/ 
streptozotocin (STZ)-induced type 2 diabetic rats.

\section{Materials and Methods}

\section{Experimental animals}

White male albino rats weighting 140-160g were used as in the present investigation. They were obtained from the animal house of Faculty of Medicine, Cairo University, Giza, Egypt. The chosen animals were housed in polypropylene cages at normal atmospheric temperature $\left(24 \pm 2^{\circ} \mathrm{C}\right)$ as well as normal 12 hours light/dark cycle. All animal procedures were approved by the Institutional Animal Ethics Committee of the Faculty of Medicine, Cairo University.

\section{Induction of type $\mathbf{2}$ diabetes mellitus}

The rats received HFD (58\% fat, $25 \%$ protein and $17 \%$ carbohydrate, as a percentage of total kcal) ad libitum. The composition and preparation of HFD were described by Reed et al [16]. After 4 weeks, rats were injected intraperitoneally (i.p.) with $35 \mathrm{mg} / \mathrm{kg}$ streptozotocin (STZ; Sigma, USA) dissolved in cold citrate buffer ( $\mathrm{pH} \mathrm{4.5)}$ in a dose volume of $1 \mathrm{ml} / \mathrm{kg}$ [17]. Seven days after STZ injection, rats were screened for blood glucose levels. Rats having glucose levels more than $200 \mathrm{mg} / \mathrm{dl}$, after $2 \mathrm{~h}$ of glucose $(3 \mathrm{~g} / \mathrm{kg})$ intake were considered diabetic.

\section{Experimental design}

Eighteen diabetic and 6 normal rats were divided into 4 groups, each consisting of $\operatorname{six}(\mathrm{N}=6)$ animals as following:

Group 1 (Control): normal rats received normal diet and the vehicle $1 \%$ carboxy methyl cellulose (CMC) by gastric intubation daily for 4 weeks and served as control rats.

Group 2 (Diabetic): diabetic rats received 1\% CMC by gastric intubation daily for 4 weeks.

Group 3 (Diabetic + 50mg BBR): diabetic rats received $50 \mathrm{mg} / \mathrm{kg}$ berberine (Sigma, USA) [9] dissolved in 1\% CMC by gastric intubation daily for 4 weeks.

Group 4 (Diabetic + 100mg BBR): diabetic rats received $100 \mathrm{mg} / \mathrm{kg}$ berberine [18] dissolved in 1\% CMC by gastric intubation daily for 4 weeks.

The rats were allowed to continue to feed on their diets until the end of the study. Twenty-four hr after the last treatment, the rats were fasted overnight, sacrificed and blood samples were collected for analysis.

\section{Biochemical study}

Glucose levels were determined using reagent kit purchased from Spin react (Spain) according to Trinder [19] method. Glycogen content in the liver was assayed following the method of Seifter, et al. [20]. Total cholesterol and triglycerides were estimated using reagent kit purchased fromVitro Scientific (Egypt) according to the method of Allain, et al. [21] and Fossati and Prencipe [22], respectively. HDL-cholesterol concentration was measured according to the method of Allain, et al. [21] using kits purchased from Spinreact (Spain).Serum free fatty acids
(FFAs) were estimated according to the method of Harris [23].

Serum LDL- and vLDL cholesterol were calculated using the equations:

$$
\text { vLDL=Triglycerides } / 5
$$

$$
\text { LDL }=\text { Total cholesterol }-\left(\left[\frac{\text { Triglycerides }}{5}\right]+\text { HDL }- \text { cholesterol }\right)
$$

Cardiovascular risk indices were calculated according to Ross [24], as follows:

$$
\begin{aligned}
& \text { Cardiovascular risk index } 1=\frac{\text { Total cholesterol }}{\mathrm{HDL}-\text { cholesterol }} \\
& \text { Cardiovascular risk index } 2=\frac{\text { LDL }- \text { cholesterol }}{\mathrm{HDL}-\text { cholesterol }}
\end{aligned}
$$

Antiatherogenic index (AAI) was determined according to the following equation [25]:

$$
\text { AAI } \%=\frac{\text { HDL }- \text { cholesterol } \times 100}{\text { Total cholesterol }- \text { HDL }- \text { cholesterol }}
$$

Serum aspartate aminotransferase (AST), creatine kinase (CK-MB) and lactate dehydrogenase (LDH) activities were assayed using reagent kits (Biosystems, Spain) according to the methods of Schumann and Klauke [26], Kachmar and Moss [27] and Teitz and Andresen [28], respectively.

\section{Determination of serum insulin and adiponectin and Homeostasis Model of Insulin Resistance (HOMA-IR)}

Serum insulin and adiponectin were determined using specific ELISA kits (R\&D systems, USA) following the manufacturer's instructions. The insulin resistance was evaluated by homeostasis model assessment estimate of insulin resistance (HOMA-IR) as follows [29]:

$$
\text { HOMAIR }=\frac{\text { Fasting insulin }(\mu \mathrm{U} / \mathrm{ml}) \times \text { Fasting glucose }(\mathrm{mmol} / \mathrm{L})}{22.5}
$$

\section{Statistical analysis}

The obtained data were analyzed by the one-way ANOVA followed by Tukey's test post hoc analysis using Graphpad Prism 5 (San Diego, CA, USA). The results were presented as mean \pm standard error (SEM) and a $\mathrm{P}$ value $<0.05$ was considered significant.

\section{Results}

\section{BBR attenuates hyperglycemia in HFD/STZ-diabetic rats}

The HFD/STZ-induced diabetic rats showed significant $(\mathrm{P}<0.001)$ increase in fasting and post-prandial serum glucose levels when compared with the control group, as depicted in Figure $1 \mathrm{~A}$. Treatment with BBR at either 50 or $100 \mathrm{mg} / \mathrm{kg}$ for 4 weeks significantly $(\mathrm{P}<0.001)$ improved both fasting and postprandial glucose levels in diabetic rats. Liver glycogen content showed a significant $(\mathrm{P}<0.01)$ decrease in HFD/STZinduced diabetic rats when compared with the control rats 
(Figure 1B). Oral supplementation of $50 \mathrm{mg} / \mathrm{kg}$ BBR produced a significant $(\mathrm{P}<0.05)$ amelioration in liver glycogen content. Similarly, treatment of the diabetic with $100 \mathrm{mg} / \mathrm{kg}$ BBR significantly $(\mathrm{P}<0.05)$ increased liver glycogen content when compared to the diabetic group
凹

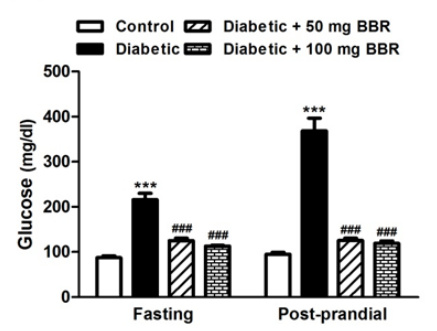

回

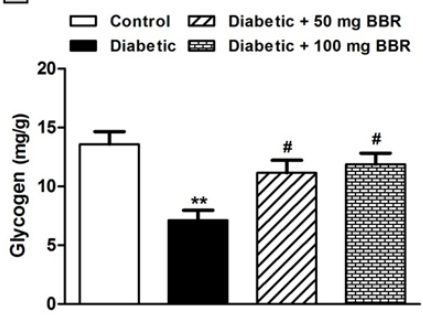

Figure 1: Effect of $B B R$ on (A) blood glucose and (B) liver glycogen levels in diabetic rats. Results are mean $\pm S E M(N=6) .{ }^{*} P<0.01$ and ${ }^{* * *} \mathrm{P}<0.001$ vs Control. \#P<0.05 and \#\#\#P<0.001 vs Diabetic group.

\section{BBR alleviates insulin sensitivity in HFD/STZ-diabetic} rats

In comparison with the control group, the HFD/STZ-induced Diabetic rats showed a significant $(\mathrm{P}<0.001)$ decrease in serum insulin levels, as depicted in Table 1 . Treatment of the diabetic rats with 50 as well as $100 \mathrm{mg} / \mathrm{kg}$ BBR significantly $(\mathrm{P}<0.001)$ ameliorated serum insulin levels when compared with the diabetic control rats. The higher BBR dose markedly $(\mathrm{P}<0.01)$ increased serum insulin levels as compared to the lower dose. In the same context, diabetic rats showed a significant $(\mathrm{P}<0.001)$ increase in HOMA-IR when compared with the control rats. Supplementation of BBR significantly decreased HOMA-IR index at either $50 \mathrm{mg}(\mathrm{P}<0.05)$ or $100 \mathrm{mg} / \mathrm{kg}(\mathrm{P}<0.01)$ dose (Table 1$)$.
Table 1: Effect of BBR on serum insulin and HOMA-IR.

\begin{tabular}{|c|c|c|}
\hline & Insulin & HOMA-IR \\
\hline & $(\mu \mathrm{U} / \mathrm{ml})$ & \\
\hline Control & $22.95 \pm 1.59$ & $4.99 \pm 0.31$ \\
\hline Diabetic & $13.36 \pm 0.74^{* * *}$ & $7.76 \pm 0.51^{* * *}$ \\
\hline Diabetic + 50mg BBR & $19.41 \pm 0.89 * * \# \# \#$ & $5.93 \pm 0.29 \#$ \\
\hline Diabetic $+100 \mathrm{mg}$ BBR & $23.03 \pm 0.58 \# \# \# \$ \$$ & $5.53 \pm 0.24 \# \#$ \\
\hline F-Prob. & $P<0.001$ & $\mathrm{P}<0.001$ \\
\hline
\end{tabular}

Data are Mean \pm SEM, $(\mathrm{N}=6)$.

${ }^{* *} \mathrm{P}<0.01$ and ${ }^{* * *} \mathrm{P}<0.001$ versus Control.

$\# \mathrm{P}<0.05, \# \# \mathrm{P}<0.01$ and \#\#\# $<0.001$ versus Diabetic.

$\$ \$ P<0.01$ versus Diabetic + 50mg BBR.

\section{$B B R$ reduces hyperlipidemia in HFD/STZ-diabetic rats}

A

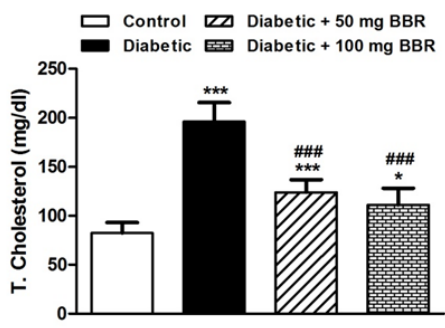

D

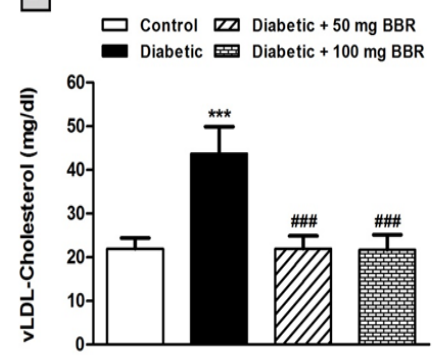

B

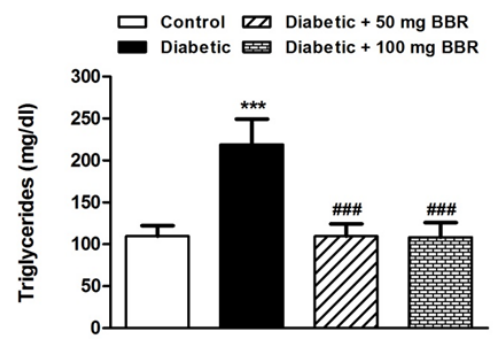

E

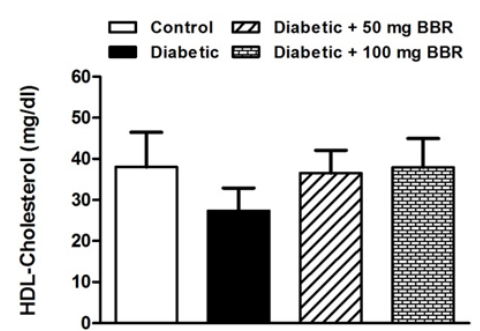

C

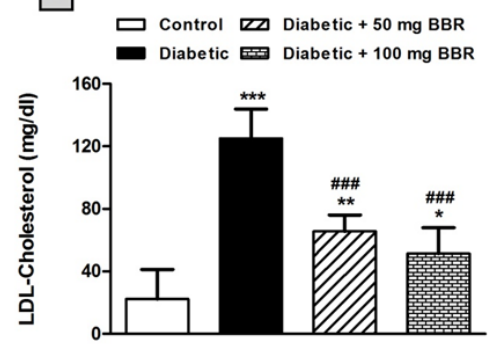

$\mathbf{F}$

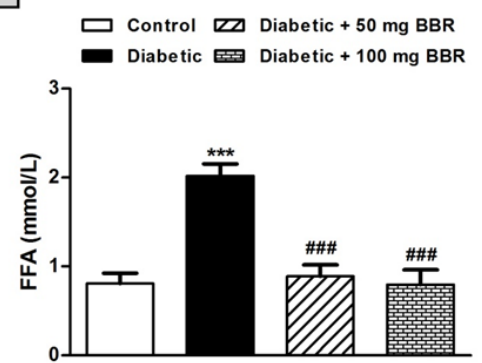

Figure 2: Effect of BBR on (A) total cholesterol, (B) triglycerides, (C) LDL-cholesterol, (D) vLDL-cholesterol, (E) HDL-cholesterol and (F) free fatty acids levels in diabetic rats. Results are mean \pm SEM $(N=6)$. ${ }^{* \star} P<0.001$ vs Control and \#\#\#P<0.001 vs Diabetic group. 
The present data showed significant $(\mathrm{P}<0.001)$ increase in serum total cholesterol (Figure 2A), triglycerides (Figure 2B), LDL-cholesterol (Figure 2C), vLDL-cholesterol (Figure 2D) and FFA (Figure 2F) levels in HFD/STZ induced diabetic rats when compared to the normal control rats. Treatment of HFD/STZadministered rats with $50 \mathrm{mg} / \mathrm{kg}$ BBR significantly $(\mathrm{P}<0.001)$ improved serum cholesterol, triglycerides and FFA levels when compared to diabetic control rats. The higher BBR dose $(100 \mathrm{mg} /$ $\mathrm{kg}$ ) ameliorated all parameters of the lipid profile and as well as FFA levels. Serumlevels of HDL-cholesterol showed nonsignificant $(\mathrm{P}>0.05)$ variation between all studied groups as represented in (Figure 2E).

\section{BBR exerts cardioprotective effect in HFD/STZ-diabetic rats}
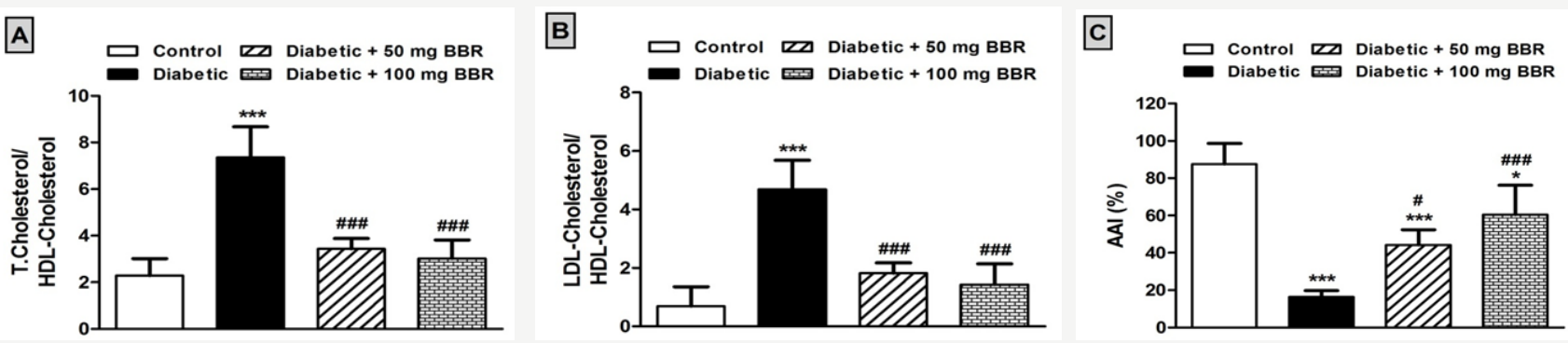

Figure 3: Effect of BBR on cardiovascular risk indices (A \& B) and antiatherogenic index (C) in diabetic rats. Results are mean \pm SEM $(N=$ 6). ${ }^{*} \mathrm{P}<0.05$ and ${ }^{* * *} \mathrm{P}<0.001$ vs Control. $\# \mathrm{P}<0.05$ and \#\#P<0.001 vs Diabetic group.

To investigate the cardio-protective effect of BBR in diabetic rats, we determined its effect on cardiovascular risk and atherogenic indices, and serum activities of AST, CK-MB and LDH. As depicted in Figure 3, HDF/STZ-induced diabetic rats exhibited a significant $(\mathrm{P}<0.001)$ increase in $\mathrm{T}$. cholesterol/ HDL-cholesterol ratio when compared to their respective control group (Figure 3A). Similarly, the LDL-cholesterol/HDLcholesterol ratio showed a significant increase in HDF/STZinduced diabetic rats when compared with the control group (Figure 3B). On the other hand, HDF/STZ-induced diabetic rats exhibited a significantly $(\mathrm{P}<0.001)$ decreased antiatherogenic index value when compared with the control rats (Figure $3 \mathrm{C}$ ).
A

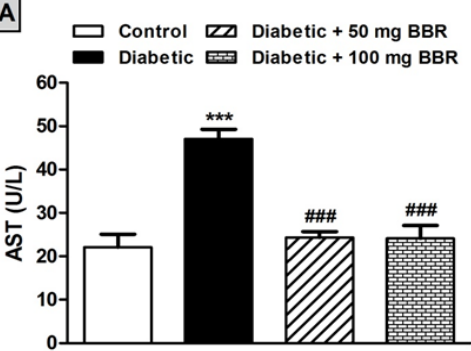

B

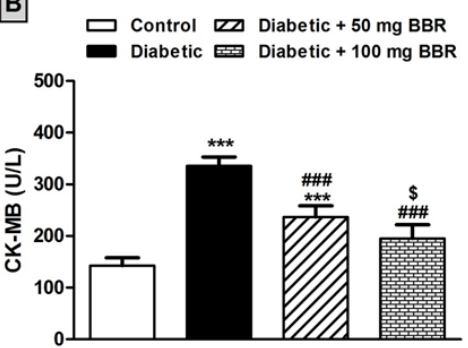

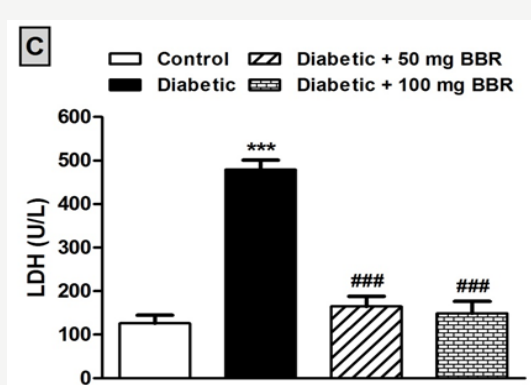

Figure 4: Effect of BBR on (A) AST, (B) CK-MB and (C) LDH activities in serum of diabetic rats. Results are mean $\pm S E M(N=6)$. ${ }^{* * *} P<0.001$ vsControl, \#\#P<0.001 vs Diabetic and $\$ \mathrm{P}<0.05$ vs Diabetic + 50mg BBR.

Treatment of the diabetic rats with $50 \mathrm{mg} / \mathrm{kg}$ BBR significantly improved the cardiovascular risk $(\mathrm{P}<0.001)$ and antiatherogenic indices $(\mathrm{P}<0.05)$. The higher dose of BBR produced a significant $(\mathrm{P}<0.001)$ improvement in all indices in diabetic rats. Concerning the cardiac function marker enzymes, HDF/STZ-induced diabetic rats showed a significant $(\mathrm{P}<0.001)$ increase in serum AST (Figure 4A), CK-MB (Figure 4B) and LDH (Figure 4C) when compared with the control rats. Treatment of the diabetic rats with either dose of BBR significantly $(\mathrm{P}<0.001)$ reduced serum activities of AST, CK-MB and LDH.

\section{BBR increase serum levels of adiponectinin HFD/STZ- diabetic rats}

The Data illustrated in Figure 5 showed a significant $(\mathrm{P}<0.001)$ decrease in serum adiponectin levels of the diabetic rats received HFD and STZ when compared with their corresponding control rats. Oral administration of either 50 or $100 \mathrm{mg} / \mathrm{kg}$ BBR markedly $(\mathrm{P}<0.001)$ alleviated serum adiponectin levels in HFD/ STZ-induced diabetic rats.

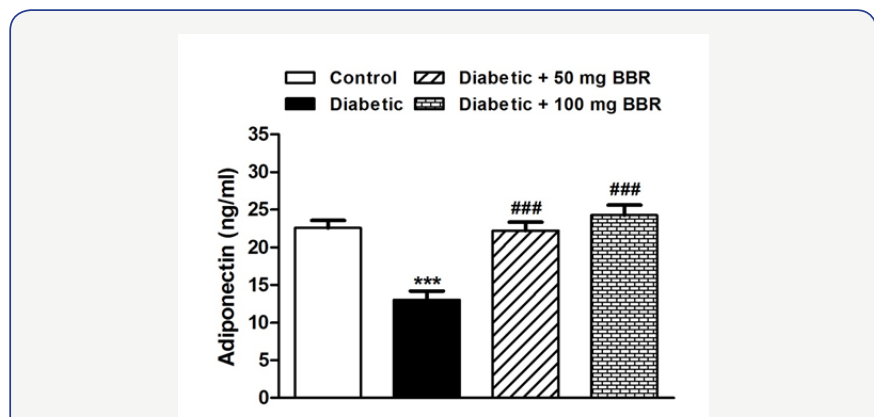

Figure 5: Effect of BBR on serum adiponectinin diabetic rats. Results are mean \pm SEM $(N=6) .{ }^{* * *} \mathrm{P}<0.001$ vsControl and \#\#P<0.001 vs Diabetic. 


\section{Discussion}

In HFD/STZ-induced diabetic animals, our data showed significant increase in fasting and post-prandial glucose levels. Similar findings have been demonstrated in our previous studies Mahmoud et al. $[17,30]$. STZ is known to induce rapid destruction of pancreatic $\beta$-cells leading to impaired glucose stimulated insulin release and insulin resistance, both of which are marked features of type 2 diabetes [31]. The elevated blood glucose is a result of reduced glucose uptake in muscle and adipose tissue [32], and increased gluconeogenesis, hepatic glucose production [33] and glycogen breakdown [34].

BBR at either dose markedly ameliorate blood glucose levels in HFD/STZ-induced diabetic rats. Accordingly, BBR decreased fasting and post-prandial blood glucose levels in HFD-induced obese rats [35,36], low dose of STZ and HFD diabetic rats [11,12], and leptin receptor-deficient $\mathrm{db} / \mathrm{db}$ mice [35]. Concerning BBR's anti-hyperglycemic mechanism, it has been reported that BBR stimulates glycolysis, suppresses hepatic gluconeogenesis and increases insulin secretion through activation of 5 -adenosine monophosphate kinase (AMPK) [37-39]. Through the same mechanism, BBR increased glucose transporter 4 (GLUT4) translocation and improved insulin sensitivity in H9c2 cardiomyocytes [39].

The anti-hyperglycemic effect of BBR could be connected to its ability to increase insulin secretion and glucose storage as glycogen in the liver of HFD/STZ-induced type 2 diabetic rats. Previous data have demonstrated the ability of BBR to stimulate insulin secretion in HFD-fed rat [40] and repair destructed or exhausted islets [41]. In addition, liver glycogen may be considered a reliable marker for assessing anti-hyperglycemic potential of any drug [42]. Generally, decreased hepatic glycogen synthesis and glycolysis, and increased hepatic glucose production are the major symptoms in type 2 diabetes [43]. Our results revealed an enormous depletion in hepatic glycogen content which were in accordance to those of Lavoie and Van de Werve [44], and Ahmed et al. [45,46].

In the present study, the increased liver glycogen content after treatment with berberine could be attributed to amelioration of the glycogenolytic and gluconeogenic pathways secondary to the increase of insulin levels in the blood. In diabetic patients, changes in concentrations of plasma lipids are complications frequently observed and certainly contribute to the development of coronary heart disease (CHD) [47]. Abnormalities in lipid metabolism play a key role in the occurrence of atherosclerosis in patients with diabetes [48]. The present data showed significant hyperlipidemia in HFD/STZ-induced diabetic rats as previously reported $[45,49,50]$. Treatment with of the diabetic rats with BBR significantly improved all parameters of the lipid profile, demonstrating anti-hyperlipidemic effect.

In the same context, BBR has been reported to decrease plasma lipids in high-fat diet induced obese rats and in diabetic rats fed with high-cholesterol diet $[12,51,52]$. The lipid lowering effect of BBR may be due to increasing insulin secretion or stabilization of the hepatic LDL receptor (LDLR) by stimulated extracellular signal-regulated kinase-dependent pathway [53]. Moreover, BBR reduced circulating FFA in HFD/STZ-induced rats. Decreasing blood FFA has been proposed as a potent strategy for prevention and/or treatment of insulin resistance [54]. Therefore, the decreased level of serum FFA by BBR may participate in its insulin sensitizing effects.

CHD is a life threatening diabetes complication and its risk increases two- or more folds in diabetes [29]. Dyslipidemia in diabetes has been reported to be strongly associated with CHD [55]. Increased triglycerides and total cholesterol levels and decreased HDL-cholesterol represent atherogeniclipid profile, which leads to the development of CHD [56]. As a favorable effect on lipid profile was observed following treatment with BBR, this indicated that it might help prevent the progression of CHD. In addition, several atherogenic indices such as total cholesterol/ HDL-cholesterol and LDL-cholesterol/HDL-cholesterol have been used to predict CHD risk [57]. Reduction of these indices in BBR supplemented diabetic rats strongly supported the notion that BBRsupplementation may lead to reduction in the risk of developing CHD.

The cardioprotective effect of BBR was further confirmed through assessment of AST, CK-MB and LDH which were significantly ameliorated in the serum of diabetic rats. This myocardial protective effect of BBR appears to be mediated not only through alleviating glucose homeostasis and lipid metabolism. Studies on ischemia/reperfusion-induced myocardial infarction [58] and type 2 diabetic rats [59] demonstrated that BBR exerts cardioprotective effect through modulation of the sympathetic activity of myocardium. Moreover, we hypothesized that the increased adiponectin levels may have a role in the beneficial effect of BBR in diabetic rats. In the present study, HFD/STZ diabetic rats exhibited diminished serum adiponectin levels as we previously reported $[46,60]$, an effect that was reversed following administration of BBR.

Reduced levels of serum adiponectin have been reported to be associated with the etiology of obesity and type 2 diabetes [61]. Studies have demonstrated that adiponectin stimulates AMPK and regulates glucose metabolism [62], enhances glucose transport and fat oxidation in muscle [63], reduces hepatic glucose production [62], and activates peroxisome proliferator activated receptor- $\alpha$ with subsequently decreased liver and muscle TG content [64]. In conclusion, the ameliorative effect of BBR on carbohydrate and lipid variables in diabetes may be attributed to its insulin releasing capacity, lipid lowering effect, and increasing adiponectin levels.

\section{Funding}

This research received no specific grant from any funding agency in the public, commercial, or not-for-profit sectors. 


\section{References}

1. Tripathi BK, Srivastava AK (2006) Diabetes mellitus: complications and therapeutics. Med Sci Monit 12(7): 130-147.

2. Sharma AK, Bharti S, Goyal S, Arora S, Nepal S, et al. (2011) upregulation of PPAR $\gamma$ by Aeglemarmelos ameliorates insulin resistance and $\beta$-cell dysfunction in high fat diet fed-streptozotocin induced type 2 diabetic rats. Phytother Res 25(10): 1457-1465.

3. Weir GC, Bonner Weir S (2004) Five stages of evolving beta-cell dysfunction during progression to diabetes. Diabetes 53(S3): S16-S21.

4. International Diabetes Federation (IDF) (2015) IDF Diabetes Atlas. (7 $7^{\text {th }}$ edn.) International Diabetes Federation, Brussels, Belgium.

5. Geirch JE (2003) Contributions of insulin-resistance and insulinsecretory defects to the pathogenesis of type 2 diabetes mellitus. Mayo Clin Proc 78(4): 447-456.

6. Cho BJ, Im EK, Kwon JH, Lee KH, Shin HJ, et al. (2005) Berberine inhibits the production of lysophosphatidylcholine-induced reactive oxygen species and the ERK1/2 pathway in vascular smooth muscle cells. Mol Cell 20: 429-434

7. Yu HH, Kim KJ, Cha JD, Kim HK, Lee YE, et al. (2005) Antimicrobial activity of berberine alone and in combination with ampicillin or oxacillin against methicillinresistant Staphylococcus aureus. J Med Food 8(4): 454-461.

8. Choi BH, Ahn IS, Kim YH, Park JW, Lee SY, et al. (2006) Berberine reduces the expression of adipogenic enzymes and inflammatory molecules of 3T3-L1 adipocyte. ExpMol Med 38: 599-605.

9. Germoush MO, Mahmoud AM (2014) Berberine mitigates cyclophosphamide-induced hepatotoxicity by modulating antioxidant status and inflammatory cytokines. J Cancer Res Clin Oncol 140(7): 1103-1109.

10. Mahmoud AM, Germoush MO, Soliman AS (2014) Berberine attenuates isoniazid-induced hepatotoxicity by modulating peroxisome proliferator-activated receptor gamma, oxidative stress and inflammation. Int J Pharmacol 10(8): 451-460.

11. Leng SH, Lu FE, Xu LJ (2004) Therapeutic effects of berberine in impaired glucose tolerance rats and its influence on insulin secretion. Acta Pharmacol Sin 25(4): 496-502.

12. Yin J, Chen M, Tang J, Li F, Zhou L, et al. (2004) Effects of berberine on glucose and lipid metabolism in animal experiment. Chin J Diabetes 12(3): 215-218.

13. Blüher M (2009) Adipose tissue dysfunction in obesity. Exp Clin Endocrinol Diabetes 117(6): 241-250.

14. Attie AD, Scherer PE (2009) Adipocyte metabolism and obesity. J Lipid Res 50: S395-399.

15. Maedler K, Sergeev P, Ris F, Oberholzer J, Joller-Jemelka HI, et al (2002) Glucose-induced beta cell production of IL-1beta contributes to glucotoxicity in human pancreatic islets. J Clin Invest 110: 851-860.

16. Reed MJ, Meszaros K, Entes LJ, Claypool MD, Pinkett JG, et al. (2000) A new rat model of type 2 diabetes, the fat-fed, streptozotocin- treated rat. Metabolism 49(11): 1390-1394.

17. Mahmoud AM, Ashour MB, Abdel-Moneim A, Ahmed OM (2012) Hesperidin and naringin attenuate hyperglycemia-mediated oxidative stress and proinflammatory cytokine production in high fat fed/ streptozotocin-induced type 2 diabetic rats. J Diabetes Complications 26(6): 483-490.

18. Mojarad TB, Roghani M (2014) The anticonvulsant and antioxidant effects of berberine in kainate-induced temporal lobe epilepsy in rats. Basic Clin Neurosci 5(2): 124-130.
19. Trinder P (1969) Determination of glucose in blood using glucose oxidase with an alternative oxygen acceptor. Ann ClinBiochem 6(1): 24-27.

20. Seifter S, Dayton S, Novic B, Muntwyler E (1950) The estimation of glycogen with anthrone reagent. Arch Biochem 25(1): 191-200.

21. Allain CC, Poon LS, Chan CS, Richmond W, Fu PC (1974) Enzymatic determination of total serum cholesterol. Clin Chem 20(4): 470-475.

22. Fossati P, Prencipe L (1982) Serum triglycerides determined colorimetrically with an enzyme that produces hydrogen peroxide. Clin Chem 28(10): 2077-2080.

23. Harris RJ (1974) Plasma nonesterified fatty acid and blood glucose levels in healthy and hypoxemic newborn infants. Pediatrics 84(4): 578-584.

24. Ross R (1992) The pathogenesis of atherosclerosis. In: Braunwald E (Ed.), Heart Disease: A Textbook of Cardiovascular Medicine. ( $4^{\text {th }}$ edn). WB Saunders, Philadelphia, USA, pp: 1106-1124.

25. Guido S, Joseph T (1992) Effect of chemically different calcium antagonists on lipid profile in rats fed on a high fat diet. Indian J Exp Biol 30(4): 292-294.

26. Schumann G, Klauke R (2003) New IFCC reference procedures for the determination of catalytic activity concentrations of five enzymes in serum: Preliminary upper reference limits obtained in hospitalized subjects. Clin Chim Acta 327(1-2): 69-79.

27. Kachmar JF, Moss DW (1976) Falinaslovpoglavlja. In: Tietz NW (Ed.), Fundamentals of Clinical Chemistry. ( $2^{\text {nd }}$ edn). WB Saunders, Philadelphia, USA, pp: 682.

28. Tietz NW, Andresen BD (1986) Textbook of Clinical Chemistry. WB Saunders, Philadelphia, USA.

29. Haffner SM (2000) Coronary heart disease in patients with diabetes. N Engl J Med 342(14): 1040-1042.

30. Mahmoud AM, Ahmed OM, Ashour MB, Abdel-Moneim A (2015) In vivo and in vitro antidiabetic effects of citrus flavonoids; A study on the mechanism of action. Int J Diabetes Dev Ctries 35(3): 250-263.

31. Farswan M, Mazumder PM, Parcha V (2009) Modulatory effect of an isolated compound from Syzygiumcumini seeds on biochemical parameters of diabetes in rats. Int J Green Pharm 3: 128-133.

32. Beck-Nielsen H (2002) Insulin resistance: organ manifestations and cellular mechanisms. Ugeskr Laeger. 164(16): 2130-2135.

33. Raju J, Gupta D, Rao AR, Yadava PK, Baquer NZ (2001) Trigonellafoenumgraecum (fenugreek) seed powder improves glucose homeostasis in alloxan diabetic rat tissues by reserving the altered glycolytic, gluconeogenic and lipogenic enzymes. Mol Cell Biochem 224: 45-51

34. Gold AH (1970) The effect of diabetes and insulin on liver glycogen synthetase activation. J Biol Chem 245(4): 903-905.

35. Lee YS, Kim WS, Kim KH, Yoon MJ, Cho HJ, et al. (2006) Berberine, a natural plant product, activates AMP-activated protein kinase with beneficial metabolic effects in diabetic and insulin-resistant states. Diabetes 55(8): 2256-2264.

36. Yin J, Xing H, Ye J (2008) Efficacy of berberine in patients with type 2 diabetes mellitus. Metabolism 57(5): 712-717.

37. KoBS, Choi SB, Park SK, Jang JS, Kim YE, et al. (2005) Insulin sensitizing and insulinotropic action of berberine from Cortidis rhizome. Biol Pharm Bull 28(8): 1431-1437.

38. Hu Y, Davies GE (2010) Berberine inhibits adipogenesis in high-fat dietinduced obesity mice. Fitoterapia 81(5): 358-366. 
39. Chang W, Zhang M, Li J, Meng Z, Wei S, et al. (2013) Berberine improves insulin resistance in cardiomyocytes via activation of 5 -adenosine monophosphate-activated protein kinase. Metabolism 62(8): 11591167.

40. Zhou JY, Zhou SW, Zhang KB, Tang JL, Guang LX, et al. (2008) Chronic effects of berberine on blood, liver glucolipid metabolism and liver PPARs expression in diabetic hyperlipidemic rats. Biol Pharm Bull 31(6): 1169-1176.

41. Zhou S, Zhou S, Tang J, Zhang K, Guang L, et al. (2009) Protective effect of berberine on beta cells in streptozotocin- and high-carbohydrate/ high-fat diet-induced diabetic rats. Eur J Pharmacol 606(1): 262-268.

42. Grover JK, Vats V, Rathi SS (2000) Antihyperglycemic effect of Eugenia jambolana and Tinosporacordifolia in experimental diabetes and their effects on key metabolic enzymes involved in carbohydrate metabolism. J Ethnopharmacol 73(3): 461-470.

43. Jung UJ, Lee MK, Jeong KS, Choi MS (2004) The hypoglycemic effects of hesperidin and naringin are partly mediated by hepatic glucoseregulating enzymes in C57BL/KsJ-db/db mice. J Nutr 134(10): 24992503.

44. Lavoie L, Van de Werve G (1991) Hormone-stimulated glucose production from glycogen in hepatocytes from streptozotocin diabetic rats. Metabolism 40(10): 1031-1036

45. Ahmed OM, Abdel-Moneim A, Abulyazid I, Mahmoud AM (2010) Antihyperglycemic, antihyperlipidemic and antioxidant effects and the probable mechanisms of action of Rutagraveolens and rutin in nicotinamide/streptozotocin diabetic albino rats. Diabetol Croat 39(1): 15-32.

46. Ahmed OM, Mahmoud AM, Abdel-Moneim A, Ashour MB (2012) Antidiabetic effects of hesperidin and naringin in type 2 diabetic rats. Diabetol Croat 41(2): 53-67.

47. Wold LE, Ceylan IAF, Ren J (2005) Oxidative stress and stress signaling: menace of diabetic cardiomyopathhy. Acta Pharmacol Sinica 26(8) 908-917.

48. Keenoy BMY, Campenhout VA, Aerts P, Vertommen, Abrams P, et al. (2005) Time course of oxidative stress status in the postprandial and postabsorptive states in type 1 diabetes mellitus: relationship to glucose and lipid changes. J Am College Nutr 24(6): 474-485.

49. Tan BKH, Tan CH, Pushparaj PN (2005) Anti-diabetic activity of the semi-purified fractions of Averrhoabilimbi in high fat diet fed streptozotocin-induced diabetic rats. Life Sci 76(24): 2827-2839.

50. Zhang H, Wei J, Xue R, Wu JD, Zhao W, et al. (2010) Berberine lowers blood glucose in type 2 diabetes mellitus patients through increasing insulin receptor expression. Metabolism 59(2): 285-292.
51. Kong W, Wei J, Abidi P, Lin M, Inaba S, et al. (2004) Berberine is a novel cholesterol-lowering drug working through a unique mechanism distinct from statins. Nat Med 10(12): 1344-1351.

52. LQ Tang, W Wei, LM Chen, S Liu (2006) Effects of berberine on diabetes induced by alloxan and a high-fat/high-cholesterol diet in rats. J Ethnopharmacol 108(1): 109-115.

53. Lee S, Lim HJ, Park JH, Lee KS, Jang Y, et al. (2007) Berberine induced LDLR up-regulation involves JNK pathway. Biochem Biophys Res Commun 362(4): 853-857.

54. Na LX, Zhang YL, Li Y, Liu LY, Li R, et al. (2010) Curcumin improves insulin resistance in skeletal muscle of rats. Nutr Metab Cardiovasc Dis 21(7): 1-8.

55. Goldstein DE (1995) How much do you know about glycated hemoglobin testing. Clin Diabetes 13(4): 60-63.

56. Garber AJ (2002) Attenuating CV risk factors in patient with diabetes: clinical evidence to clinical practice. Diabetes Obes Metab 4(1): S5-12.

57. Grover SA, Levington C, Paquet S (1999) Identifying adults at low risk for significant hyperlipidemia: a validated clinical index. J Clin Epidemiol 52(1): 49-55.

58. Chang W, Zhang M, Li J, Meng Z, Xiao D, et al. (2012) Berberine attenuates ischemia-reperfusion injury via regulation of adenosine$5=-$ monophosphate kinase activity in both non-ischemic and ischemic areas of the rat heart. Cardiovasc Drugs Ther 26(6): 467-478.

59. Wang L, Li H, Wang S, Liu R, Wu Z, et al. (2014) Erratum to: Enhancing the antitumor activity of berberine hydrochloride by solid lipid nanoparticle encapsulation. AAPS Pharm Sci Tech 15(5): 1355.

60. Mahmoud AM, Germoush MO, Elgebaly HA, Elsayed KNM, Hassan S, et al. (2014) Antidiabetic and insulin sensitizing effects of brown seaweeds in streptozotocin/nicotinamide diabetic rats. Asian J Pharm Clin Res 7(4): 74-78.

61. Statnick MA, Beavers LS, Conner LJ, Corominola H, Johnson D, et al (2000) Decreased expression of apM1 in Omental and subcutaneous adipose tissue of humans with Type 2 diabetes. Int J Exp Diabetes Res 1(2): 81-88

62. Yamauchi T, Kamon J, Minokoshi Y, Ito Y, Waki H, et al. (2002) Adiponectin stimulates glucose utilization and fatty-acid oxidation by activating AMP-activated protein kinase. Nat Med 8(11): 1288-1295.

63. Tomas E, Tsao TS, Saha AK, Murrey HE, Zhang CC, et al. (2002) Enhanced muscle fat oxidation and glucose transport by ACRP30 globular domain: Acetyl-CoA carboxylase inhibition and AMP-activated protein kinase activation. Proc Natl Acad Sci 99(25): 16309-16313.

64. MacDougald OA, Burant CF (2007) The rapidly expanding family of adipokines. Cell Metab 6(3): 159-161.

\section{Your next submission with Juniper Publishers} will reach you the below assets

- Quality Editorial service

- Swift Peer Review

- Reprints availability

- E-prints Service

- Manuscript Podcast for convenient understanding

- Global attainment for your research

- Manuscript accessibility in different formats

( Pdf, E-pub, Full Text, Audio)

- Unceasing customer service

Track the below URL for one-step submission

https://juniperpublishers.com/online-submission.php 